\title{
The Association between Pathological Internet Use and Comorbid Psychopathology: A Systematic Review
}

\author{
V. Carlia ${ }^{a}$ T. Durkee ${ }^{a}$ D. Wasserman ${ }^{a} \quad$ G. Hadlaczky ${ }^{a} \quad$ R. Despalins ${ }^{a} \quad$ E. Kramarz ${ }^{a}$ \\ C. Wasserman b, d M. Sarchiapone ${ }^{d}$ C.W. Hoven ${ }^{c} \quad$ R. Brunner ${ }^{e} \quad$ M. Kaess ${ }^{e, f}$

 \\ Stockholm, Sweden; ${ }^{b}$ Department of Child and Adolescent Psychiatry, Columbia University-New York State \\ Psychiatric Institute, and 'Department of Epidemiology, Mailman School of Public Health, Columbia University, \\ New York, N.Y., USA; d Department of Health Sciences, University of Molise, Campobasso, Italy; ${ }^{\text {eSection for }}$ \\ Disorders of Personality Development, Department of Child and Adolescent Psychiatry, Center of Psychosocial

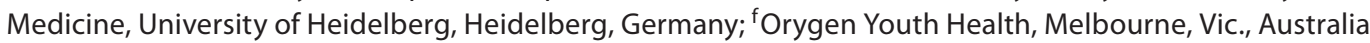

\section{Key Words}

Pathological Internet use $\cdot$ Internet addiction •

Psychopathology · Depression • Anxiety - Attention

deficit and hyperactivity disorder - Obsessive-compulsive

symptoms $\cdot$ Social phobia $\cdot$ Hostility/aggression

\begin{abstract}
Background: Pathological Internet use (PIU) has been conceptualized as an impulse-control disorder that shares characteristics with behavioral addiction. Research has indicated a potential link between PIU and psychopathology; however, the significance of the correlation remains ambiguous. The primary objective of this systematic review was to identify and evaluate studies performed on the correlation between PIU and comorbid psychopathology; the secondary aims were to map the geographical distribution of studies, present a current synthesis of the evidence, and assess the quality of available research. Sampling and Methods: An electronic literature search was conducted using the following databases: MEDLINE, PsycARTICLES, PsychINFO, Global Health, and Web of Science. PIU and known synonyms were included in the search. Data were extracted based on PIU
\end{abstract}

and psychopathology, including depression, anxiety, symptoms of attention deficit and hyperactivity disorder (ADHD), obsessive-compulsive symptoms, social phobia and hostility/aggression. Effect sizes for the correlations observed were identified from either the respective publication or calculated using Cohen's $d$ or $R^{2}$. The potential effect of publication bias was assessed using a funnel plot model and evaluated by Egger's test based on a linear regression. Results: The majority of research was conducted in Asia and comprised cross-sectional designs. Only one prospective study was identified. Twenty articles met the preset inclusion and exclusion criteria; $75 \%$ reported significant correlations of PIU with depression, $57 \%$ with anxiety, $100 \%$ with symptoms of ADHD, $60 \%$ with obsessive-compulsive symptoms, and $66 \%$ with hostility/aggression. No study reported associations between PIU and social phobia. The majority of studies reported a higher rate of PIU among males than females. The relative risks ranged from an OR of 1.02 to an OR of 11.66. The strongest correlations were observed between PIU and de-

V.C. and T.D. contributed equally to this article and therefore both should be considered as first authors.

\section{KARGER \\ Fax +41613061234 \\ E-Mail karger@karger.ch}

www.karger.com (c) 2012 S. Karger AG, Basel

0254-4962/13/0461-0001\$38.00/0

Accessible online at:

www.karger.com/psp
Michael Kaess, MD

Orygen Youth Health

35 Poplar Road

Parkville, VIC 3052 (Australia)

Tel.+61 39342 2800,E-Mail michael.kaess@unimelb.edu.au 
pression; the weakest was hostility/aggression. Conclusions: Depression and symptoms of ADHD appeared to have the most significant and consistent correlation with PIU. Associations were reported to be higher among males in all age groups. Limitations included heterogeneity in the definition and diagnosis of PIU. More studies with prospective designs in Western countries are critically needed.

Copyright $\odot 2012$ S. Karger AG, Basel

\section{Introduction}

Internet use has grown substantially over the past few decades, accounting for nearly 2 billion users globally [1]. Although studies indicate that the majority of Internet users are among adolescents and young adults [2-4], research shows that Internet usage is rising among older populations [5]. Given the broad spectrum of Internet users, it is important to understand the potential risks involved in compulsive use. Public health concerns are emerging concerning the propensity of compulsive Internet use developing into pathological behaviors.

The pathway from adaptive to pathological Internet use (PIU) appears to be ambiguous [6]; however, there are noteworthy characteristics distinguishing the two groups. Among adaptive users, the Internet appears to serve as a supportive tool, rather than a source of identity. There is evidence showing that adaptive use facilitates new and existing relationships through frequent and accessible online communication; it can promote socialization and self-esteem [7], as well as decrease loneliness [8]. Conversely, evidence has indicated that pathological Internet users tend to spend more hours online compared to adaptive users (e.g. online $\geq 10-20 \mathrm{~h} /$ week) $[9,10]$ and are prone to use the Internet for specific online activities (e.g. compulsive gambling [11], pornography [12-14], extreme role-playing fantasies [15-17], and excessive gaming [18]). Research suggests that PIU may not only reflect a riskbehavioral syndrome, but also a clinical disorder, due to the presence of withdrawal and tolerance symptoms [19].

PIU is conceptually modeled as an impulse-control disorder that does not involve an intoxicant, and it shares qualities related to behavioral addiction [20]. Behavioral addiction, as suggested by Griffiths [21], is a paradigm that is based on the Diagnostic and Statistical Manual of Mental Disorders (DSM-IV) criteria for pathological gambling and substance-dependence; it comprises six explicit traits: salience, mood modification, tolerance, withdrawal symptoms, conflict and relapse. It is hypothesized that the respective attributes of behavioral addic- tion are present among pathological Internet users [2224]. On this basis, PIU has been proposed for inclusion in the DSM-V as a behavioral addiction, but without success $[25,26]$. Instead, PIU will be inserted in the DSM-V appendix, stipulating that more research is required before a diagnosis can be incorporated into the DSM nosological system [27]; this could potentially be a contributing factor to the lack of a universal diagnostic criteria for PIU, inevitably influencing outcomes of PIU-related studies.

The prevalence of PIU varies among populations. Epidemiological studies have reported considerable variations in the prevalence of PIU among adolescents and young adults, ranging from 0.9 to $37.9 \%$ [28-31] in Asia and 2 [27] to $18.3 \%$ [32-36] in Europe. In the US general population, PIU prevalence varies between 0.3 [37] and $8.1 \%$ [38]. It is evident that there are extreme variances in PIU prevalence across countries and cultures; further analysis on the psychological effect of prevalent PIU is necessary.

There may be severe mental and emotional implications for those with PIU; it should be noted that PIU may also occur as a consequence of ongoing mental health issues. Research has indicated a potential correlation between PIU and impulsivity [39, 40], depression [41, 42], anxiety [43], psychosis [44], obsessive-compulsive symptoms [45], and social anxiety/phobia [46]; however, data so far has been contradictory with regards to comorbid psychopathology. To the best of our knowledge, an evidence-based systematic review examining the association between PIU and psychopathological traits is still lacking [47]; scientific-based outcomes are required for preventive and treatment efforts.

The primary aim of this systematic review was to identify and evaluate studies performed on the correlation between PIU and comorbid psychopathology; secondary aims were to assess the diagnostic criteria for measuring PIU and outcome measures of psychopathology, map the geographical distribution of studies, and evaluate levels of evidence. Based on the available literature, the following psychopathologies were included: depression [48], anxiety [49], symptoms of attention deficit and hyperactivity disorder (ADHD) [50], obsessivecompulsive symptoms [51], social phobia [52], and hostility/aggression [53].

\section{Methods}

An electronic literature search was conducted using the following databases: MEDLINE, PsycARTICLES, PsychINFO, Global Health, and Web of Science. There were no restrictions on 
language, time, or publication status. Key identifiers used were 'Internet addiction' or 'Internet addiction disorder' or 'Internet dependency' or 'pathological Internet use' or 'problematic Internet use' or 'compulsive Internet use' or 'excessive Internet use' or 'computer addiction', combined with the identifiers 'depression' or 'anxiety' or 'obsessive-compulsive' or 'ADHD' or 'social phobia' or 'hostility' or 'aggression'.

Articles were systematically and independently reviewed by the authors; assessments were performed regarding the study type, study population, methodology, outcome measures, effect sizes, and interpretation of results. The inclusion criteria for studies involved population-based studies with a large sample size (>200 subjects), ascertained diagnostic criteria for PIU, subsequent reporting on the correlation between PIU and predetermined psychopathologies, and the psychometric outcome measures assessing psychopathology. Studies were excluded if there were no clear diagnostic criteria, a significant sampling bias or small sample size ( $<200$ subjects), only focused on specific subtypes of PIU (e.g. compulsive online gambling), and/or were case studies and/or treatment assessment.

Studies were rated according to the scheme proposed by the Oxford Centre for Evidence-Based Medicine Results [54] and evaluated by the following criteria: observation of a full or partial association, significance level, and adjustments for confounders. Full association was considered when a correlation was found for both sexes after multivariate analyses. If a correlation was identified for only one gender, it was classified as a partial association. The geographical distribution of studies was also mapped.

Effect size of the associations was identified by either the original publications or calculated using the data of the respective publications. Identified effect sizes were reported mostly in odds ratios (OR), with one publication reporting in hazard ratios (HR); the calculated effect sizes were either Cohen's $d$ or $\mathrm{R}^{2}$. In order to compare the different associations, the effect sizes $\mathrm{d}$ and $\mathrm{R}^{2}$ were stated as small, moderate, or large, according to Cohen [55]; OR were converted into these groups according to Chinn [56]. The effect sizes were interpreted accordingly: small $\left(\mathrm{d}=0.2, \mathrm{R}^{2}=0.01\right.$, $\mathrm{OR}=1.45)$, moderate $\left(\mathrm{d}=0.5, \mathrm{R}^{2}=0.06, \mathrm{OR}=2.50\right)$, and large $\left(\mathrm{d}=0.8, \mathrm{R}^{2}=0.14, \mathrm{OR}=4.25\right)$.

The potential effect of publication bias was assessed for the relationship between PIU and depression. This effect could not be estimated for other psychopathologies, given that too few publications met the inclusion criteria. The publication bias was explored for depression by a funnel plot model. This graph was created by plotting the log OR against the standard error of these measures [57]. A funnel plot graph, shaped with a symmetrical distribution, would indicate no publication bias, whereas an asymmetric plot would suggest bias; this could be due to unreported studies, small sample sizes, or low significance levels [58]. The asymmetry of the funnel plot was statistically evaluated by Egger's test, which is based on a linear regression of the normalized effect estimate (estimate divided by its standard error) against precision (reciprocal of the standard error) [59]. If a publication bias was found, a trim and fill method [60] was used to estimate the number of missing studies and adjusted accordingly. This method is commonly used to remove the asymmetric side of the funnel plot by artificially imputing the missing studies, based on the other side of the graph.

Association between PIU and Comorbid Psychopathology

\section{Results}

After deleting duplicate studies, a total of 185 articles were screened and identified through the present systematic search. As a result, 32 studies were immediately excluded, as they were based on other Internet-related topics. Twenty articles were included in the respective systematic review in accordance with the inclusion and exclusion criteria (fig. 1) [61].

\section{Description of Included Studies}

The included articles comprised one prospective cohort study (level of evidence: 1B) [62], two case-control studies (level of evidence: 3B) [63, 64], and 17 cross-sectional studies (level of evidence: 4) [65-81], as illustrated in table 1 . Half of the studies $(n=10)$ in this review targeted adolescent groups, seven studies targeted young adults, and three studies were aimed at the general population; all studies examined both genders.

\section{Geographical Distribution of Studies}

Overall, the majority of studies performed on PIU were implemented in Asian countries. Eleven studies were performed in China [62, 64-68, 70, 73, 76, 77, 81] and five in South Korea [72, 74, 75, 79, 82]. The remaining studies were conducted in the US [71], UK [63], Norway [69], and Turkey [80].

\section{Methods Assessing PIU}

There are no standardized diagnostic criteria for identifying PIU; however, there are several assessment instruments that are often utilized in PIU research. The most common psychometric instrument(s) for measuring PIU is the Young's Diagnostic Questionnaire for Internet Addiction (YDQ) [83]. The YDQ is built upon the DSM-IV diagnostic criteria for pathological gambling and has been employed and validated in other studies [32, 35]. In the YDQ, the diagnosis is based on a pattern of Internet usage that results in a clinical impairment or distress in accordance to the presence of the following criteria: (1) preoccupation with the Internet; (2) need for longer amounts of time online to achieve satisfaction; (3) repeated unsuccessful efforts to control, cut back, or stop Internet use; (4) restlessness, moodiness, depression, or irritability when attempting to cut down or stop Internet use; (5) staying online longer than originally intended; (6) jeopardizing or risking the loss of a significant relationship, job, or educational opportunity because of the Internet; (7) lying to family members, therapists, or others to conceal the extent of involvement with the Internet; 
Fig. 1. PRISMA 2009 flow diagram [61].

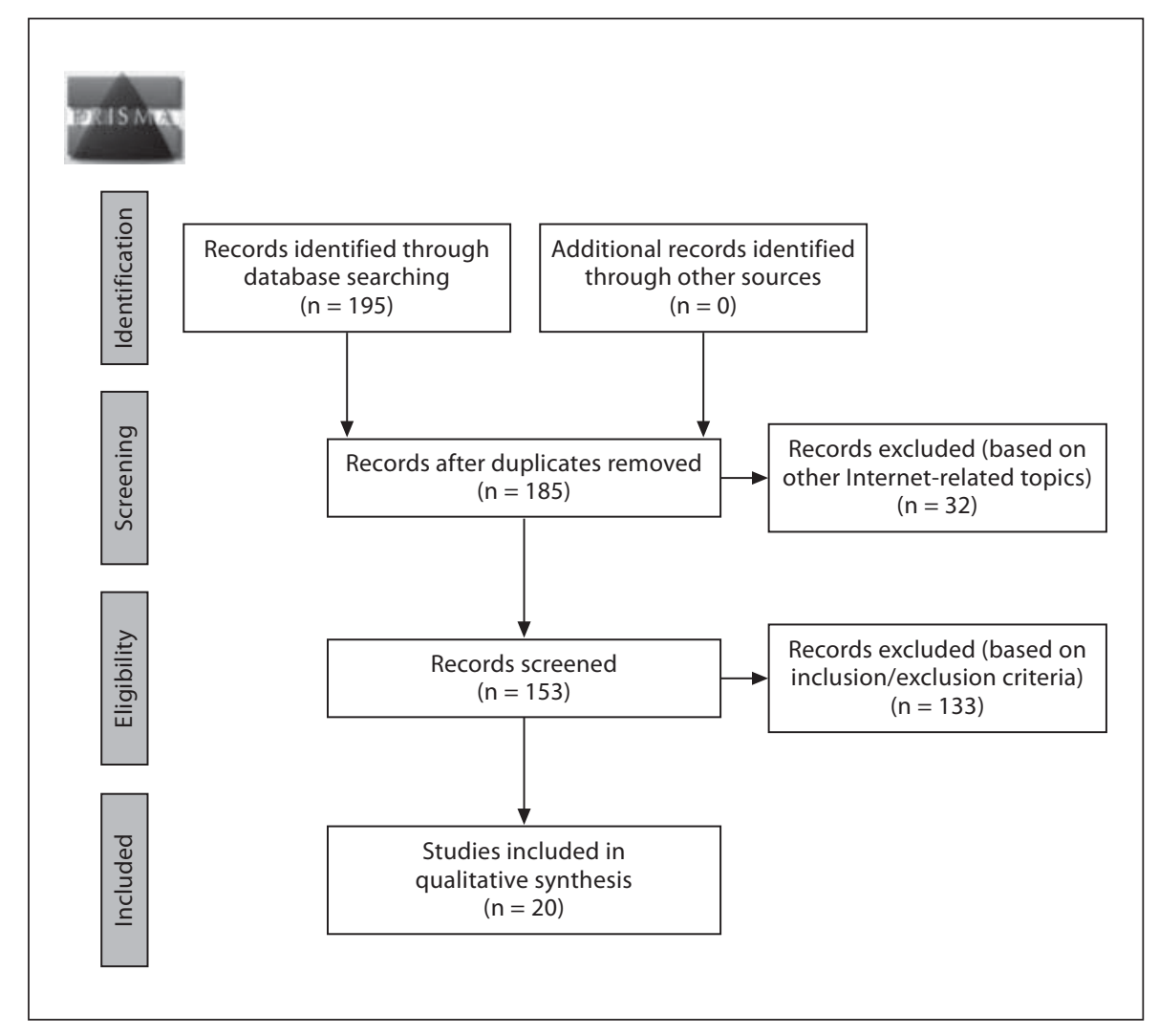

and (8) using the Internet as a way of escaping from problems or relieving a dysphoric mood $[20,83]$. The respective eight criteria are evaluated through eight 'yes' or 'no' questions with a total score ranging from $0-8$. Those scoring $\geq 5$ were classified as pathological. In the present review, two studies used the YDQ to measure PIU [64, 69]. Based on the YDQ, Young [84] further modified the assessment instrument to measure severity, thereby establishing a 20 -item questionnaire that measures mild, moderate, and severe levels of PIU. Referred to as the Internet Addiction Test (IAT), the psychometric properties of this instrument have been evaluated and ascertained as valid and reliable [85]. The IAT was the most utilized assessment of PIU taxonomy in this review, with eight studies $[63,65,68,72,74,75,78,79]$ reporting to have used it. The second most frequently utilized instrument was the Chen Internet Addiction Scale [86], which was reported in seven studies $[62,66,67,70,73,77,81]$ in this analysis. The Chen Internet Addiction Scale is a 26 -item questionnaire, which has also been validated, and assesses five dimensions of the condition: compulsive use, withdrawal, tolerance, problems with interpersonal relationships, and time management [87]. The three residual studies employed atypical measures: Internet Usage Questionnaire [71], Diagnostic Criteria of Internet Addiction [76], and Problematic Internet Use Scale [80].

\section{Methods Assessing Psychopathology}

Measurements of psychopathology in the scrutinized studies were performed by different psychometric mechanisms. To measure depression, five studies $[62,66,71-$ 73] used the Center for Epidemiologic Studies Depression Scale; two studies $[63,80]$ used Beck's Depression Inventory; and two studies $[65,68]$ used the Zung Self-Rating Depression Scale. One study employed the Diagnostic Interview Schedule for Children with Major Depression Disorder [74]; one study utilized the Mini-International Neuropsychological Interview [76]; one study used a modified Diagnostic Scale of Excessive Internet Use, which included an assessment of depression [79]; and one study used the 12-item version of the General Health Questionnaire [80]. To measure ADHD symptoms, five studies [62, 73, 76-78] used diverse versions of the Adult ADHD Self-Report Scale. To measure anxiety, one study used the Self-Rating Anxiety Scale [68], and one study used single-item questions [69] for both anxiety and ob- 


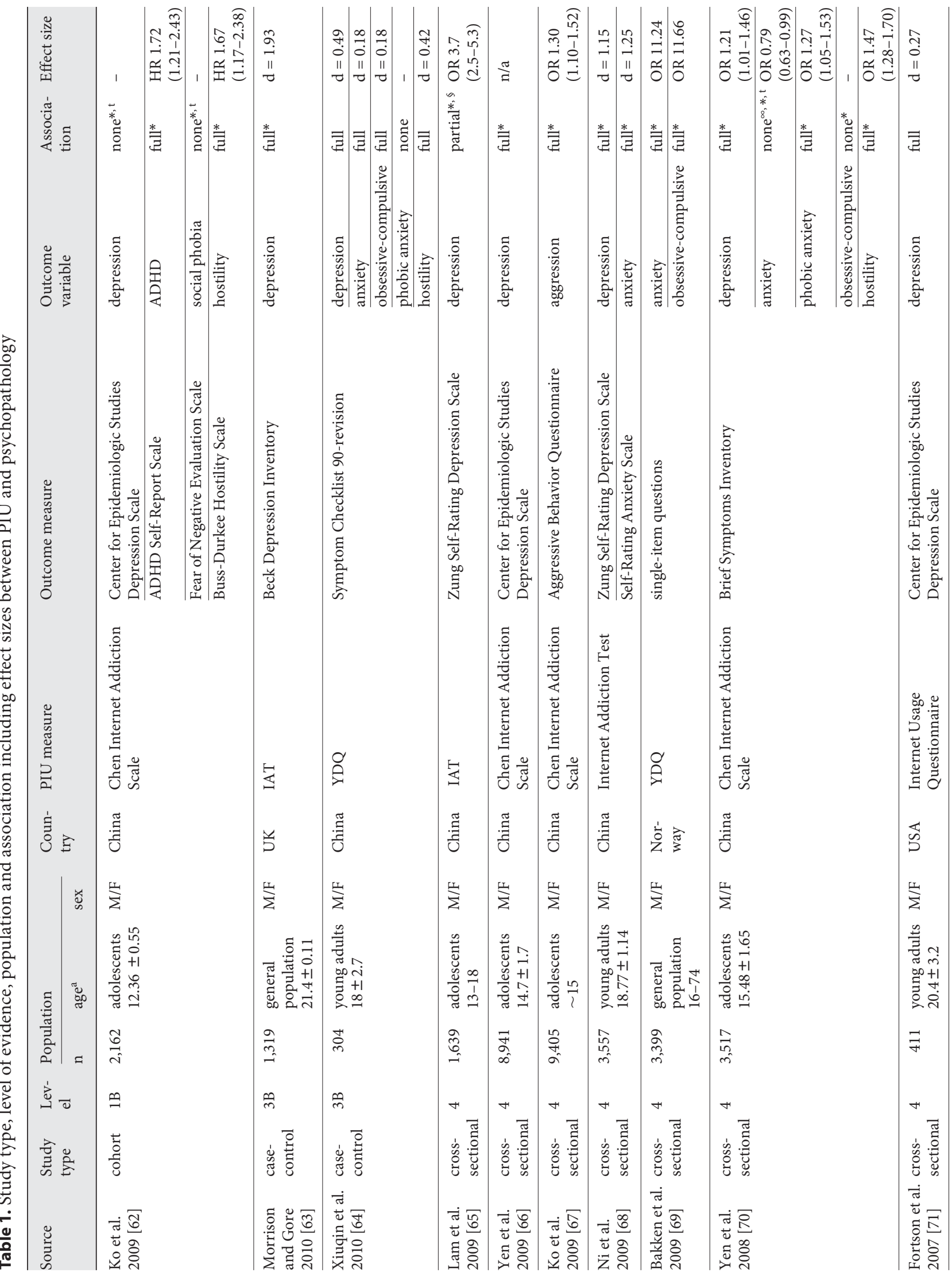







Table 2. Number of observed associations identified between PIU and psychopathology stratified by effect size

\begin{tabular}{lllllll}
\hline Effect size & $\begin{array}{l}\text { Depres- } \\
\text { sion }\end{array}$ & $\begin{array}{l}\text { Anx- } \\
\text { iety }\end{array}$ & $\begin{array}{l}\text { Symp- } \\
\text { toms of } \\
\text { ADHD }\end{array}$ & $\begin{array}{l}\text { Obsessive- } \\
\text { compulsive } \\
\text { symptoms }\end{array}$ & $\begin{array}{l}\text { Social } \\
\text { phobia }\end{array}$ & $\begin{array}{l}\text { Hostility/ } \\
\text { aggression }\end{array}$ \\
\hline Small $^{\mathrm{a}}$ & 5 & 3 & 2 & 2 & 0 & 4 \\
Moderate $^{\mathrm{b}}$ & 5 & 0 & 1 & 0 & 0 & 1 \\
Large $^{\mathrm{c}}$ & 4 & 2 & 2 & 2 & 0 & 0 \\
\hline Total & 14 & 5 & 5 & 4 & 0 & 5 \\
\hline
\end{tabular}

${ }^{\mathrm{a}} \mathrm{d}=0.2, \mathrm{R}^{2}=0.01, \mathrm{OR}=1.45 .^{\mathrm{b}} \mathrm{d}=0.5, \mathrm{R}^{2}=0.06, \mathrm{OR}=2.50$. ${ }^{c} \mathrm{~d}=0.8, \mathrm{R}^{2}=1.14, \mathrm{OR}=4.25$.

sessive-compulsive symptoms. To measure obsessivecompulsive symptoms, one study used the Maudsley Obsessive Compulsive Inventory [72]. To measure hostility/ aggression, one study used the Buss-Durkee Hostility Inventory [62], one study used the Chinese Hostility Inventory-Short Form [73], and one study used the Aggressive Behavior Questionnaire [67]. To measure social phobia, one study used the brief version of the Fear of Negative Evaluation Scale [62], and one study used the Social Phobia Inventory [73]. In two of the studies [64, 75], the Symptom Checklist 90-Revision [88] was used to assess multiple conditions, including depression, anxiety, phobic anxiety, obsessive-compulsive, and hostility. Another study used the Brief Symptoms Inventory [70] to measure the corresponding psychopathologies.

\section{Association between PIU and Psychopathology}

Significant correlations were reported between PIU and ADHD symptoms, depression, hostility/aggression, and obsessive-compulsive symptoms. Full associations were reported most frequently between PIU and symptoms of ADHD [62, 73, 76-78] (100\% of examined studies) and depression $[63,66,68,70-74,79-81]$ (75\% of examined studies). A full association with obsessive-compulsive symptoms $[64,69,72]$ and hostility/aggression $[62,64,67,70]$ was reported in 60 and $66 \%$ of examined studies, respectively.

\section{Effect Size of Observed Associations}

The relative risks of the associations between PIU and psychopathology ranged from an OR of 1.02 [73] to an OR of 11.66 [69]. The strongest correlations were observed between PIU and depression, whereas the weakest were identified between PIU and hostility/aggression. In total, the effect size of correlations comprised 10 large $[63,68$,
$69,72,76,78-80], 7$ moderate $[64,65,76,77,81]$, and 16 small associations $[62,64,67,70,71,73-75]$ (table 2).

\section{PIU and Age Groups}

The studies included in the present review focused on three age groups as target populations: total population, young adults, and adolescents. Three studies examined the total population, which comprised diverse age groups, and the association between PIU and depression $[63,79]$, anxiety, and obsessive-compulsive symptoms [69]. In all three studies targeting the total population, a large effect size was found in the correlation between PIU and depression, anxiety, and obsessive-compulsive symptoms. Three of six studies targeting young adults identified an association, with a large effect size, between PIU and depression [68, 80], anxiety [68], and symptoms of ADHD [76]. The remaining 11 studies targeted adolescent populations. Of these 11 studies, two indicated a large effect size when assessing the correlation between PIU and depression, ADHD [78], and obsessive-compulsive symptoms [72]. In relation to the age-group distribution, large effect sizes were found in all studies targeting the total population, 50\% targeting young adults, and $18 \%$ targeting adolescents.

\section{PIU and Gender}

Eleven studies [63, 65-67, 69, 70, 72, 75-78] found significantly higher rates of PIU among males compared to females. Three of the studies $[68,71,74]$ found no significant gender differences. No study reported higher PIU rates among females.

\section{PIU and Regions}

In Asia, large effect sizes were observed in four studies $[68,76-78]$ concerning the association between PIU and depression, symptoms of ADHD, anxiety, and obsessivecompulsive symptoms. All European studies showed large effect sizes between PIU and correlated depression $[63,80]$, anxiety, and obsessive-compulsive symptoms [69]. The US study reported a small effect size between PIU and depression [71].

\section{PIU and Depression}

The majority of studies examined depression as an exposure variable. Concerning the overall correlation between PIU and depression, 12 studies found full associations, three studies found a partial association, and one study found no association. There were two case-control studies $[63,64]$ and 10 cross-sectional $[66,68,70-74,79-$ 81] studies that found a full association between PIU and 
depression. Among those, one case-control [64] and three cross-sectional $[71,74,79]$ studies did not control for covariates. Moreover, after adjusting for confounders, three cross-sectional studies $[65,75,76]$ found partial associations in male subjects only. However, in the only cohort study [62], after adjusting for covariates, there was no correlation found. Among the correlations detected, the effect sizes for the association with depression comprised four large $[63,68,79,80]$, five moderate $[64,65,72,76,81]$, and five small $[70,71,73-75]$ observed effects.

\section{PIU and Anxiety}

In the correlation between PIU and anxiety, four studies (one study on phobic anxiety) found a full association, whereas three studies (one study on phobic anxiety) found no association. The full associations identified comprised one case-control study [64], but did not control for confounding variables, and three cross-sectional studies [68-70]. Only one study found a negative correlation between PIU and anxiety in a univariate analysis; however, this was not statistically significant after controlling for confounding variables in a multivariate analysis [70]. Moreover, in the same study, though no association was found between PIU and anxiety, there was a significant association found with phobic anxiety, even after adjusting for confounders. However, in one of the casecontrol studies [64], there was no correlation found with phobic anxiety. Overall, correlations were identified for anxiety in three studies and phobic anxiety in one study, thereby resulting in four positive correlations for anxiety. The three residual studies found no association. The observed effect sizes in the association between PIU and anxiety were split between two large $[68,69]$ and two small $[64,70]$, with no study identified as moderate. Three studies included social phobia as an outcome variable in their analysis. These studies comprised one cohort $[62]$ and two cross-sectional $[73,76]$ designs. After controlling for covariates, no correlation was found between PIU and social phobia.

\section{PIU and Symptoms of ADHD}

Five studies included symptoms of ADHD as an exposure variable; all five studies found full associations between PIU and ADHD. In all respective studies, correlations were confirmed after controlling for covariates. The studies comprised one cohort [62] and four cross-sectional designs [73, 76-78]. The effect sizes for the detected correlations between PIU and ADHD symptoms were also split between two large $[76,78]$ and two small $[62$, 73], with one reporting moderate [77] results.

\section{PIU and Obsessive-Compulsive Symptoms}

Five studies investigated the association between PIU and obsessive-compulsive symptoms. Three studies [64, $69,72]$ reported full associations, one study [75] found a partial association for males only, and one study [70] found no association. Studies that found full associations comprised one case-control [64], which did not control for covariates, and two cross-sectional $[69,72]$ designs, which did control for covariates. The remaining two studies were both cross-sectional, and the results were reported after controlling for confounding factors. The effect sizes determined in the papers that reported associations between PIU and obsessive-compulsive symptoms were large in two cases $[69,72]$ and small $[64,75]$ in the other two.

\section{PIU and Hostility/Aggression}

Six studies examined the association between PIU and hostility/aggression. Among those, four studies [62, 64, $67,70]$ found full association, one study [73] found a partial correlation for males only, and one study [75] found no correlation. The four studies that found full associations included one cohort [62], one case-control [64], and two cross-sectional designs $[67,70]$. The remaining two studies both had a cross-sectional design. All but the case-control study adjusted for confounding factors. The weakest correlations were observed between PIU and hostility/aggression. The results illustrated one study with moderate [64] and four with small $[62,67,70,73]$ effect sizes.

\section{Publication Bias}

Analysis of the publication bias was only possible for studies reporting on PIU and depression, as there were a statistically insufficient number of studies reporting on the remaining psychopathologies in both the scientific literature and in the present review. Among the 16 studies reporting on PIU and depression, there were only six studies that reported OR; thus, the respective six studies on PIU and depression were included in the funnel plot model (fig. 2). The results illustrated that all six studies were asymmetrically located on the right side of the graph, indicating publication bias. The publication bias was statistically significant at the $5 \%$ risk level $(p=0.022)$. In order to adjust for this asymmetrical bias, the trim and fill method was implemented. This approach ascertained that an additional three studies reporting an OR were lacking on the other side of the funnel plot. A fill random effects meta-analysis using the six original studies and the three imputed missing studies were performed to cor- 


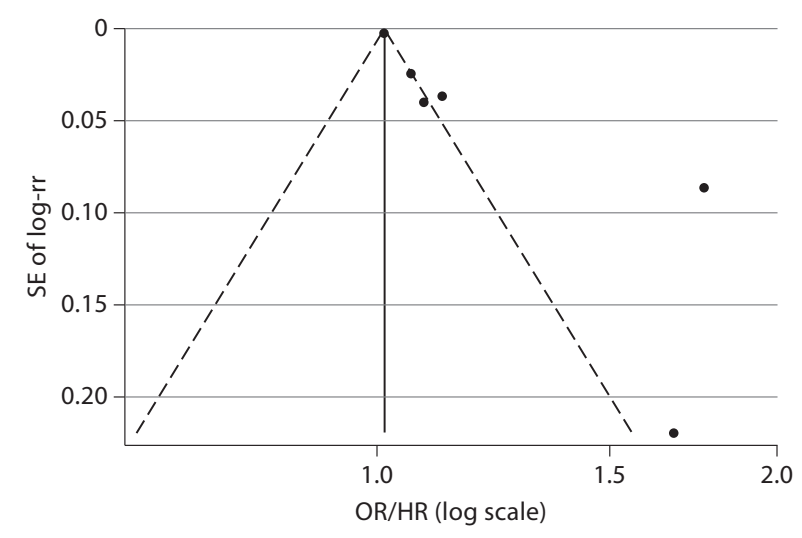

Fig. 2. Funnel plot with pseudo-95\% confidence limits.

rect for the bias. The results of this meta-analysis suggest that the association between PIU and depression might occur due to publication bias. It must be underscored that these results should be interpreted cautiously, as research has noted at least 10 original studies are required in this model to obtain robust results $[89,90]$.

\section{Discussion}

In the present systematic review on PIU and psychopathology, $75 \%$ of the studies reported significant associations with depression, $57 \%$ with anxiety, $100 \%$ with symptoms of ADHD, 60\% with obsessive-compulsive symptoms, and $66 \%$ with hostility/aggression. No study reported associations between PIU and social phobia. In general, the strongest association was found between PIU and depression; however, a preliminary analysis of a potential publication bias necessitates caution in its interpretation. Notwithstanding, it should be noted that, in general, only a marginally small number of publications were reported on PIU in the literature. On this basis, it is uncertain if the association found between PIU and psychopathologies occurred on the basis of an actual significant relationship or the result of publication bias. This will have to be assessed once there are more epidemiological data reported in the field of Internet behavioral addictions.

In all analyses, the effect sizes examined indicated that the strongest association was found between PIU and depression, whereas the weakest correlation was between
PIU and hostility/aggression. Large effects were observed in studies performed in Europe and studies that targeted all age groups. Based on these results, it is plausible that subjects with PIU are at higher risk for comorbid psychopathology. On the other hand, it is also possible that psychopathology leads to PIU. Longitudinal data is required to assess the causal interaction; however, only one study included a prospective cohort design, and only two studies used a case-control design. The remaining 17 studies employed a cross-sectional design. Although the crosssectional design is reliable in determining associations, it is unable to report on the causal relationship between PIU and specific psychopathologies. We have clear information concerning the association between PIU and psychopathology, but scarce data on causality. It is recommended that more prospective cohort studies be performed within this scientific field.

The strong association between PIU and symptoms of ADHD reported in the literature is not surprising. Persons with ADHD are easily bored and thrive for instant gratification. Given the widespread availability of the Internet, individuals have access to a constant stream of information and may engage in more activities at the same time. Moreover, ADHD individuals often lack selfcontrol, which can, in turn, sustain an addiction to the Internet. Evidence also indicates that persons with ADHD suffer from learning disabilities [91] and dyslexia [92], social [93] and emotional impairments [94], extreme aggression, and externalizing symptoms [95]. There is also a high level of stigmatization associated with $\mathrm{ADHD}$ [96]. These could be contributing factors influencing the association between PIU and ADHD symptoms. Longitudinal analyses, which adjust for these confounding factors, are critically needed.

Remarkably, not one study found a correlation between PIU and social phobia. These results were unexpected, as it is theorized that subjects with social phobia suffer from isolation, and thus spend longer time online, which increases the propensity for dependency [62]. Another interesting finding is that only half of the studies found an association between PIU and anxiety. The link to anxiety was postulated to be a strong indicator of PIU $[97,98]$; however, this was not found in the present systematic review. There are several factors that may influence this result. Outcome measures in assessing anxiety were not equally standardized as observed in depression and symptoms of ADHD. Moreover, as often characterized in behavioral addiction disorders, dependency can serve as a coping mechanism to relieve stress and anxiety. There is also the possibility that Internet illiteracy causes 
anxiety in some users. Research indicates that the capability to navigate the Internet is linked with the level of anxiety, i.e. less Internet competence results in higher anxiety levels [99]. Internet literacy often depends on the population; adolescents tend to be more e-literate than older age groups [100], indicating higher anxiety levels among adult Internet users. Age group, gender, and geographic region all played significant roles in the relationship between PIU and anxiety.

The geographical distribution of research in this field does not appear to be homogeneous. Eighty percent of the studies depicted in this review were performed in Asia, with the majority being in China alone. The communication and technology sectors are increasing rapidly in China; statistics show that China has the highest number of Internet users worldwide. Moreover, the population of China is higher than the European Union. There are also distinctive cultural variances, such as history, religion, traditions, customs, education, and ethnic groups that affect Internet users differently. These cultural variations could potentially be involved in the intricate relationship between PIU and comorbid psychopathology. It is evident, given cultural disparities, that the results cannot automatically be interpreted in the context of other cultures and continents. Thus, more research needs to be performed in other regions of the world for eventual cross-cultural comparisons.

One of the major issues in research on PIU is the lack of a universal diagnostic criterion for assessing Internetrelated pathological behaviors. This review illustrated a wide range of diagnostic tests were used in different studies. The most common assessment instrument for measuring PIU was the IAT, followed by the Chen Internet Addiction Scale. The IAT accounts for severity of PIU, which is essential in grouping different levels of Internet users. However, these scales have limitations, e.g. they do not account for the content of preferred online activities of the Internet user. Instead, all Internet-related behaviors are pooled together, such as gambling, consumption of pornographic materials, social networking, gaming, and/or reading online news. A deeper understanding of the productive and destructive influences of Internet activities would be helpful in shedding light on the distinct mechanisms of Internet pathology, as well as distinguishing PIU from other addictions.

\section{Limitations}

Although there were no language restrictions in the database search, there is a potential risk that some nonEnglish publications were missed. However, studies in other languages, with an abstract in English, were also included in the search. The analysis did not address mediating factors that may arbitrate the link between PIU and psychopathology, e.g. drug and alcohol abuse. There is heterogeneity in the definition and diagnosis of PIU, as well as psychometric instruments used to measure psychopathology; this could potentially limit cross-national comparisons. Additionally, most studies so far are lacking detailed assessment of online-activities, despite the fact that they are likely to play an important role in the association between PIU and comorbid mental health issues. Publication bias could only be partly assessed in PIU and depression, due to the insufficient number of publications in this research field.

\section{Conclusions}

The present systematic review identified scientific studies indicating strong associations between PIU, symptoms of ADHD, and depression. Anxiety, social phobia, obsessive-compulsive symptoms, and aggression did not appear to be significant factors of PIU. Given that the majority of studies were of cross-sectional design, causal relationships could not be identified. Publication bias should also be considered when interpreting these results. Prospective cohort studies, in this area of research, are necessitated in order to detect the causal liaison between these respective variables.

It is recommended for further research to focus on larger epidemiological studies that use standardized methodologies, which can be utilized in subsequent systematic reviews. In-depth investigations that focus on the distinctive content of online activities in relation to PIU are critically needed. The information derived from such an analysis would prove essential in better understanding the idiosyncratic pathways of PIU and comorbid psychopathology.

\section{Acknowledgments}

This paper has been prepared within the framework of the Saving and Empowering Young Lives in Europe (SEYLE) project. The SEYLE project is supported through Coordination Theme 1 (Health) of the European Union Seventh Framework Program (FP7), grant agreement No. HEALTH-F2-2009-223091. The project leader and coordinator of SEYLE is Professor Danuta Wasserman, Head of the National Swedish Prevention of Mental IllHealth and Suicide (NASP), Karolinska Institutet, Stockholm, Sweden. Other members of the Executive Committee are Professor Marco Sarchiapone, Department of Health Sciences, Univer-
10

Psychopathology 2013;46:1-13
Carli et al. 
sity of Molise, Campobasso, Italy; Vladimir Carli, National Swedish Prevention of Mental Ill-Health and Suicide (NASP), Karolinska Institutet, Stockholm, Sweden; and Professor Christina Hoven and Anthropologist Camilla Wasserman, Department of Child and Adolescent Psychiatry, New York State Psychiatric Institute, Columbia University, New York, USA. The SEYLE Consortium comprises centers in 12 European countries. Site leaders for each respective center and country are: Danuta Wasserman (Karolinska Institutet, Sweden, Coordinating Centre), Christian Haring (University for Medical Information Technology, Austria), Airi Varnik (Estonian-Swedish Mental Health and Suicidology Institute, Estonia), Jean-Pierre Kahn (University of Nancy, France), Romuald Brunner (University of Heidelberg, Germany), Judit Balazs (Vadaskert Child and Adolescent Psychiatric Hospital, Hungary), Paul Corcoran (National Suicide Research Foundation, Ireland), Alan Apter (Schneider Children's Medical Centre of Israel, Tel-Aviv University, Tel Aviv, Israel), Marco Sarchiapone (University of Molise, Italy), Doina Cosman (Iuliu Hatieganu University of Medicine and Pharmacy, Romania), Dragan Marusic (University of Primorska, Slovenia), and Julio Bobes (University of Oviedo, Spain).

The authors wish to thank Peter Parzer, University of Heidelberg, for his invaluable statistical consultation for the purpose of this study.

\section{Disclosure Statement}

No conflicts of interests are present among the authors of this paper.

\section{References}

1 InternetWorldStats: Usage and Population 11 Wolfling K, Buhler M, Lemenager T, Morsen Statistics. Bogota, Miniwatts Marketing Group, 2010.

$\checkmark 2$ Bremer J: The Internet and children: advantages and disadvantages. Child Adolesc Psychiatr Clin N Am 2005;14:405-428.

- Aslanidou S, Menexes G: Youth and the Internet: uses and practices in the home. Comput Educ 2008;51:1375-1391.

4 Giles G, Price IR: Adolescent computer use: approach, avoidance, and parental control. Aust J Psychol 2008;60:63-71.

${ }_{5}$ Tak SH, Hong SH: Use of the Internet for ${ }_{15}$ health information by older adults with arthritis. Orthop Nurs 2005;24:134-138.

6 Greenfield DN: Psychological characteristics of compulsive Internet use: a preliminary analysis. Cyberpsychol Behav 1999;2: 403-412.

7 Shaw LH, Gant LM: In defense of the Internet: the relationship between Internet communication and depression, loneliness, selfesteem, and perceived social support. Cyberpsychol Behav 2002;5:157-171.

$>8$ Hamburger YA, Ben-Artzi E: The relationship between extraversion and neuroticism and the different uses of the Internet. Comput Human Behav 2000;16:441-449.

-9 Niemz K, Griffiths M, Banyard P: Prevalence of pathological Internet use among university students and correlations with self-esteem, the general health questionnaire (GHQ), and disinhibition. Cyberpsychol Behav 2005;8:562-570.

10 Tsitsika A, Critselis E, Kormas G, Filippopoulou A, Tounissidou D, Freskou A, Spiliopoulou T, Louizou A, Konstantoulaki E, Kafetzis D: Internet use and misuse: a multivariate regression analysis of the predictive factors of Internet use among Greek adolescents. Eur J Pediatr 2009;168:655-665.
C, Mann K: Gambling and Internet addiction: review and research agenda (in German). Nervenarzt 2009;80:1030-1039.

12 Fasolo CB: Internet addiction and pornophilia. Sex Disabil 2004;22:295.

13 Young KS: Internet sex addiction - risk factors, stages of development, and treatment. Am Behav Sci 2008;52:21-37.

14 Delmonico DL, Carnes PJ: Virtual sex addiction: when cybersex becomes the drug of choice. Cyberpsychol Behav 1999;2:457-463.

5 Allison SE, von Wahlde L, Shockley T, Gabbard GO: The development of the self in the era of the Internet and role-playing fantasy games. Am J Psychiatry 2006;163:381-385.

16 Chuang YC: Massively multiplayer online role-playing game-induced seizures: a neglected health problem in Internet addiction. Cyberpsychol Behav 2006;9:451-456.

$17 \mathrm{Ng} \mathrm{BD}$, Wiemer-Hastings P, Hastings W: Addiction to massively multiplayer online roleplaying games. Cyberpsychol Behav 2004;7: 298-299.

18 de Abreug CN, Karam RR, Goes DS, Spritzer DT: Internet and videogame addiction: a review (in Portuguese). Rev Bras Psiquiatr 2008;30:156-167.

19 Charlton JP: A factor-analytic investigation of computer 'addiction' and engagement. $\mathrm{Br}$ J Psychol 2002;93:329-344.

20 Dowling NA, Quirk KL: Screening for Internet dependence: do the proposed diagnostic criteria differentiate normal from dependent Internet use? Cyberpsychol Behavior 2009; 12:21-27.

21 Griffiths M: Addiction, the tobacco industry and nature. Nature 1998;392:122.

22 Shaw M, Black DW: Internet addiction: definition, assessment, epidemiology and clinical management. CNS Drugs 2008;22:353365.
23 Chou C, Condron L, Belland JC: A review of the research on Internet addiction. Educ Psychol Rev 2005;17:363-388.

24 Wanajak K, Rudd C, Wilkinson A: Definition and diagnostic criteria of Internet addiction. Int J Mental Health Nurs 2008; 17:A32-A33.

25 Block JJ: Issues for DSM-V: Internet addiction. Am J Psychiatry 2008;165:306-307.

26 Pies R: Should DSM-V designate 'Internet addiction' a mental disorder? Psychiatry (Edgmont) 2009;6:31-37.

27 Holden C: Psychiatry. Behavioral addictions debut in proposed DSM-V. Science 2010;327: 935.

28 Cao F, Su L: Internet addiction among Chinese adolescents: prevalence and psychological features. Child Care Health Dev 2007;33: 275-281.

29 Leung L: Net-generation attributes and seductive properties of the Internet as predictors of online activities and Internet addiction. Cyberpsychol Behav 2004;7:333-348.

30 Chou C, Hsiao MC: Internet addiction, usage, gratification, and pleasure experience: the Taiwan college students' case. Comput Educ 2000;35:65-80.

31 Park SK, Kim JY, Cho CB: Prevalence of Internet addiction and correlations with family factors among South Korean adolescents. Adolescence 2008;43:895-909.

32 Johansson A, Gotestam KG: Internet addiction: characteristics of a questionnaire and prevalence in Norwegian youth (12-18 years). Scand J Psychol 2004;45:223-229.

- 33 Kaltiala-Heino R, Lintonen T, Rimpela A: Internet addiction? Potentially problematic use of the Internet in a population of 12-18 year-old adolescents. Addict Res Theory 2004;12:89-96. 
-34 Pallanti S, Bernardi S, Quercioli L: The Shorter PROMIS Questionnaire and the Internet Addiction Scale in the assessment of multiple addictions in a high-school population: prevalence and related disability. CNS Spectr 2006;11:966-974.

- 35 Siomos KE, Dafouli ED, Braimiotis DA, Mouzas OD, Angelopoulos NV: Internet addiction among Greek adolescent students. Cyberpsychol Behav 2008;11:653-657.

36 Zboralski K, Orzechowska A, Talarowska M, Darmosz A, Janiak A, Janiak M, Florkowski A, Galecki P: The prevalence of computer and Internet addiction among pupils. Postepy Hig Med Dosw (Online) 2009;63:812.

-37 Aboujaoude E, Koran LM, Gamel N, Large MD, Serpe RT: Potential markers for problematic Internet use: a telephone survey of 2,513 adults. CNS Spectr 2006;11:750-755.

38 Morahan-Martin J, Schumacher P: Incidence and correlates of pathological Internet use among college students. Comput Human Behav 2000;16:13-29.

-39 Cao FL, Su LY, Liu TQ, Gao XP: The relationship between impulsivity and Internet addiction in a sample of Chinese adolescents. Eur Psychiatry 2007;22:466-471.

40 Dong G, Lu Q, Zhou H, Zhao X: Impulse inhibition in people with Internet addiction disorder: electrophysiological evidence from a Go/NoGo study. Neurosci Lett 2010;485: 138-142.

41 Tsai CC, Lin SS: Internet addiction of adolescents in Taiwan: an interview study. Cyberpsychol Behav 2003;6:649-652.

-42 Wildt BTT, Putzig I, Zedler M, Ohlmeier MD: Internet dependency as a symptom of depressive mood disorders (in German). Psychiatr Prax 2007;34:S318-S322.

$\checkmark 43$ Bernardi S, Pallanti S: Internet addiction: a descriptive clinical study focusing on comorbidities and dissociative symptoms. Compr Psychiatry 2009;50:510-516.

44 Gibbs PL: Reality in cyberspace: Analysands' use of the Internet and ordinary everyday psychosis. Psychoanal Rev 2007;94:11-38.

$\checkmark 45$ Zhang LX, Amos C, McDowell WC: A comparative study of Internet addiction between the United States and China. Cyberpsychol Behav 2008;11:727-729.

-46 Chen SH, Yang JF: Internet addiction, social anxiety, and preference attribution of the virtual world. Int J Psychol 2004;39:512-512.

-47 Christakis DA: Internet addiction: a 21st century epidemic? BMC Med 2010;8:61.

-48 Sanders CE, Field TM, Diego M, Kaplan M: The relationship of Internet use to depression and social isolation among adolescents. Adolescence 2000;35:237-242.

- 49 Black DW, Moyer T: Clinical features and psychiatric comorbidity of subjects with pathological gambling behavior. Psychiatr Serv 1998;49:1434-1439.
50 Breyer JL, Botzet AM, Winters KC, Stinchfield RD, August G, Realmuto G: Young adult gambling behaviors and their relationship with the persistence of ADHD. J Gambl Stud 2009;25:227-238.

51 Blaszczynski A: Pathological gambling and obsessive-compulsive spectrum disorders. Psychol Rep 1999;84:107-113.

52 Zimmerman M, Chelminski I, Young D: Prevalence and diagnostic correlates of DSM-IV pathological gambling in psychiatric outpatients. J Gambl Stud 2006;22:255262.

53 Kim EJ, Namkoong K, Ku T, Kim SJ: The relationship between online game addiction and aggression, self-control and narcissistic personality traits. Eur Psychiatry 2008;23: 212-218.

54 CEBM: Oxford Centre for Evidence-Based Medicine - Levels of Evidence. Oxford, University of Oxford, 2010.

55 Cohen J: Statistical Power Analysis for the Behavioral Sciences. Hillsdale, Lawrence Erlbaum Associates, 1988.

56 Chinn S: A simple method for converting an odds ratio to effect size for use in meta-analysis. Stat Med 2000;19:3127-3131.

57 Cooper H, Hedges LV, Begg CB: Publication bias; in Cooper H, Hedges LV (eds): The Handbook of Research Synthesis. New York, Russell Sage Foundation, 1994, pp 399-409.

58 Dubben HH, Beck-Bornholdt HP: Systematic review of publication bias in studies on publication bias. BMJ 2005;331:433-434.

-59 Egger M, Davey Smith G, Schneider M, Minder C: Bias in meta-analysis detected by a simple, graphical test. BMJ 1997;315:629634.

60 Duval S, Tweedie R: Trim and fill: a simple funnel-plot-based method of testing and adjusting for publication bias in meta-analysis. Biometrics 2000;56:455-463.

61 Moher D, Liberati A, Tetzlaff J, Altman DG: Preferred reporting items for systematic reviews and meta-analyses: the PRISMA statement. BMJ 2009;339:b2535.

62 Ko CH, Yen JY, Chen CS, Yeh YC, Yen CF: Predictive values of psychiatric symptoms for Internet addiction in adolescents: a 2-year prospective study. Arch Pediatr Adolesc Med 2009;163:937-943.

63 Morrison CM, Gore H: The relationship between excessive Internet use and depression: a questionnaire-based study of 1,319 young people and adults. Psychopathology 2010;43: 121-126.

64 Xiuqin H, Huimin Z, Mengchen L, Jinan W, Ying Z, Ran T: Mental health, personality, and parental rearing styles of adolescents with Internet addiction disorder. Cyberpsychol Behav Soc Netw 2010;13:401-406.

65 Lam LT, Peng ZW, Mai JC, Jing J: Factors associated with Internet addiction among adolescents. Cyberpsychol Behav 2009;12:551555.
66 Yen CF, Ko CH, Yen JY, Chang YP, Cheng $\mathrm{CP}$ : Multi-dimensional discriminative factors for Internet addiction among adolescents regarding gender and age. Psychiatry Clin Neurosci 2009;63:357-364.

67 Ko CH, Yen JY, Liu SC, Huang CF, Yen CF: The associations between aggressive behaviors and Internet addiction and online activities in adolescents. J Adolesc Health 2009; 44:598-605.

68 Ni X, Yan H, Chen S, Liu Z: Factors influencing Internet addiction in a sample of freshmen university students in China. Cyberpsychol Behav 2009;12:327-330.

69 Bakken IJ, Wenzel HG, Gotestam KG, Johansson A, Oren A: Internet addiction among Norwegian adults: a stratified probability sample study. Scand J Psychol 2009; 50:121-127.

70 Yen JY, Ko CH, Yen CF, Chen SH, Chung WL, Chen CC: Psychiatric symptoms in adolescents with Internet addiction: comparison with substance use. Psychiatry Clin Neurosci 2008;62:9-16.

71 Fortson BL, Scotti JR, Chen YC, Malone J, Del Ben KS: Internet use, abuse, and dependence among students at a southeastern regional university. J Am Coll Health 2007;56: 137-144.

72 Ha JH, Kim SY, Bae SC, Bae S, Kim H, Sim M, Lyoo IK, Cho SC: Depression and Internet addiction in adolescents. Psychopathology 2007;40:424-430.

-73 Yen JY, Ko CH, Yen CF, Wu HY, Yang MJ: The comorbid psychiatric symptoms of Internet addiction: attention deficit and hyperactivity disorder (ADHD), depression, social phobia, and hostility. J Adolesc Health 2007; 41:93-98.

74 Kim K, Ryu E, Chon MY, Yeun EJ, Choi SY, Seo JS, Nam BW: Internet addiction in Korean adolescents and its relation to depression and suicidal ideation: a questionnaire survey. Int J Nurs Stud 2006;43:185-192.

75 Jang KS, Hwang SY, Choi JY: Internet addiction and psychiatric symptoms among Korean adolescents. J Sch Health 2008;78:165171.

76 Ko CH, Yen JY, Chen CS, Chen CC, Yen CF: Psychiatric comorbidity of Internet addiction in college students: an interview study. CNS Spectr 2008;13:147-153.

-77 Yen JY, Yen CF, Chen CS, Tang TC, Ko CH: The association between adult ADHD symptoms and Internet addiction among college students: the gender difference. Cyberpsychol Behav 2009;12:187-191.

78 Yoo HJ, Cho SC, Ha J, Yune SK, Kim SJ, Hwang J, Chung A, Sung YH, Lyoo IK: Attention deficit hyperactivity symptoms and Internet addiction. Psychiatry Clin Neurosci 2004;58:487-494.

79 Whang LS, Lee S, Chang G: Internet overusers' psychological profiles: a behavior sampling analysis on Internet addiction. $\mathrm{Cy}$ berpsychol Behav 2003;6:143-150. 
80 Ceyhan AA, Ceyhan E: Loneliness, depression, and computer self-efficacy as predictors of problematic Internet use. Cyberpsychol Behav 2008;11:699-701.

81 Cheung LM, Wong WS: The effects of insomnia and Internet addiction on depression in Hong Kong Chinese adolescents: an exploratory cross-sectional analysis. J Sleep Res 2011;20:311-317.

82 Yoo HJ, Cho SC, Ha JY, Yune SK, Kim SJ, Hwang J, Chung A, Sung YH, Lyoo IK: Attention deficit hyperactivity symptoms and Internet addiction. Psychiatry Clin Neurosci 2004;58:487-494.

83 Young K: Internet addiction: the emergence of a new clinical disorder. Cyberpsychol Behav 1998;1:237-244.

84 Young KS: Caught in the Net: How to Recognize the Signs of Internet Addiction And a Winning Strategy for Recovery. New York, J. Wiley, 1998.

85 Widyanto L, McMurran M: The psychometric properties of the Internet Addiction Test. Cyberpsychol Behav 2004;7:443-450.

$86 \mathrm{Ko} \mathrm{CH}$, Yen JY, Yen CF, Chen CC, Yen CN, Chen SH: Screening for Internet addiction: an empirical study on cut-off points for the Chen Internet Addiction Scale. Kaohsiung J Med Sci 2005;21:545-551.
87 Chen S, Weng L, Su Y, Wu H, Yang P: Development of Chinese Internet Addiction Scale and its psychometric study. Chin J Psychol 2003;45:279-294.

88 Derogatis LR: SCL-90: Administration, Scoring and Procedures Manual for the (Revised) Version and Other Instruments of the Psychopathology Rating Scale Series. Baltimore, Johns Hopkins University School of Medicine, 1977.

89 Monroe J: Meta-analysis for observational studies: Statistical methods for heterogeneity, publication bias and combining studies: Statistics. Los Angeles, University of California, 2007, Master degree, pp 46.

90 Sutton AJ: Methods for Meta-Analysis in Medical Research. Chichester, J. Wiley, 2000.

91 Brook U, Boaz M: Attention deficit and hyperactivity disorder (ADHD) and learning disabilities (LD): adolescents perspective. Patient Educ Couns 2005;58:187-191.

92 Eden GF, Vaidya CJ: ADHD and developmental dyslexia: two pathways leading to impaired learning. Ann NY Acad Sci 2008; 1145:316-327.

-93 Paulson JF, Buermeyer C, Nelson-Gray RO: Social rejection and ADHD in young adults: an analogue experiment. J Atten Disord 2005;8:127-135.

-94 Wehmeier PM, Schacht A, Barkley RA: Social and emotional impairment in children and adolescents with ADHD and the impact on quality of life. J Adolesc Health 2010;46:209-217.
95 Blackman GL, Ostrander R, Herman KC: Children with ADHD and depression: a multisource, multimethod assessment of clinical, social, and academic functioning. J Atten Disord 2005;8:195-207.

96 Biederman J, Faraone SV, Chen WJ: Social adjustment inventory for children and adolescents: concurrent validity in ADHD children. J Am Acad Child Adolesc Psychiatry 1993;32:1059-1064.

97 Kim HK, Davis KE: Toward a comprehensive theory of problematic Internet use: evaluating the role of self-esteem, anxiety, flow, and the self-rated importance of Internet activities. Comput Human Behav 2009;25:490-500.

98 Weinstein A, Lejoyeux M: Internet addiction or excessive Internet use. Am J Drug Alcohol Abuse 2010;36:277-283.

99 Chu A, Mastel-Smith B: The outcomes of anxiety, confidence, and self-efficacy with Internet health information retrieval in older adults: a pilot study. Comput Inform Nurs 2010;28:222-228.

100 van Deursen AJ, van Dijk JA: Internet skills performance tests: are people ready for eHealth? J Med Internet Res 2011;13:e35. 